\title{
Wahl des Zentralvorstands der FMH und für das Amt des Präsidenten
}

Anne-Geneviève Bütikofer

Generalsekretärin der FMH

\section{Vorstellung der Kandidatinnen und Kandidaten in der SÄZ}

Im Rahmen der kommenden Ärztekammer vom 7. Juni 2012 wird der Zentralvorstand der FMH für eine neue Legislatur gewählt. Wir möchten die FMH-Mitglieder, die sich bewerben, den Leserinnen und Lesern der Schweizerischen Ärztezeitung in kurzen Porträts vorstellen.
Wir bitten alle Kandidatinnen und Kandidaten, uns über kommunikation[at]fmh.ch zu kontaktieren. Gerne stellen wir Interessierten entsprechende Informationen sowie Beispiele solcher Porträts zu. Die Angaben von Bewerberinnen und Bewerbern benötigen wir bis spätestens am 19. April 2012. Die Porträts erscheinen am 16. Mai 2012 in der Schweizerischen Ärztezeitung Nummer 20/21.

\section{Election du Comité central et de la présidence de la FMH}

Anne-Geneviève Bütikofer

Secrétaire générale de la FMH

\section{Présentation des candidates et candidats dans le BMS}

Dans la perspective de la prochaine Chambre médicale du 7 juin 2012, lors de laquelle aura lieu l'élection du Comité central de la FMH pour la prochaine législature, nous souhaitons donner à chaque candidat la possibilité de se présenter aux lecteurs et lectrices du Bulletin des médecins suisses.
Nous invitons tous les candidats à prendre contact avec le service de communication de la FMH (kommunikation[at]fmh.ch). Nous leur transmettrons un document précisant les informations requises ainsi que des exemples de portraits. Les informations sur les candidats doivent nous parvenir d'ici au 19 avril au plus tard. Les portraits paraîtront dans le $n^{\circ} 20 / 21$ du Bulletin des médecins suisses du 16 mai 2012.

\section{Bringt Vorteile. Die Mitgliedschaft in der FMH.}

Wir machen uns stark für Sie. Mit engagierter Standespolitik und attraktiven Services: TarifInfoline, Rechtsauskünfte, Musterverträge.

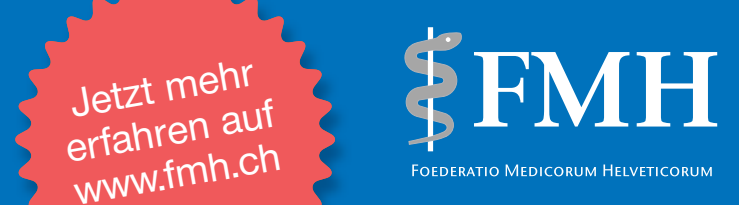

